\title{
Extremely high levels of vancomycin can cause severe renal toxicity
}

This article was published in the following Dove Press journal: Infection and Drug Resistance

\author{
Jaime Barceló-Vidal,' \\ Eva Rodríguez-García, ${ }^{2}$ \\ Santiago $\mathrm{Grau}^{3}$ \\ 'Department of Pharmacy, Hospital \\ del Mar, Parc de Salut Mar, Barcelona, \\ Spain; ${ }^{2}$ Department of Nephrology, \\ Hospital del Mar, Parc de Salut Mar, \\ Barcelona, Spain; ${ }^{3}$ Department of \\ Pharmacy, Hospital del Mar, Parc de \\ Salut Mar, Universitat Autònoma de \\ Barcelona, Barcelona, Spain
}

Correspondence: Santiago Grau Department of Pharmacy, Hospital del Mar, Parc de Salut Mar, Universitat Autònoma de Barcelona, Passeig Marítim 25-29, 08003, Barcelona, Spain

$\mathrm{Tel}+3432483154$

Fax +3432483256

Email sgrau@parcdesalutmar.cat

\begin{abstract}
Vancomycin has usually been associated with nephrotoxicity. Generally, this toxicity is presented as proximal tubular cells injury with or without necrosis and as acute interstitial nephritis. However, development of both lesions is uncommonly described in literature. We present a case of vancomycin-induced nephrotoxicity resulting in both acute interstitial nephritis and tubular cells damage confirmed by renal biopsy. Peak and trough levels of 77.11 and $63.60 \mu \mathrm{g} / \mathrm{mL}$, respectively, were obtained at the first plasma determination. After 8 more plasma determinations and several hemodialysis sessions, vancomycin levels were undetectable 1 month after therapy was stopped. To our knowledge, this is the case report with the highest vancomycin trough levels developing both lesions and describing total vancomycin washout after a biopsy-proven vancomycin toxicity. In conclusion, early vancomycin therapeutic drug monitoring should be performed in order to avoid toxicities where, as seen in our patient, antibiotic exposure could last around 1 month after last dose administration.
\end{abstract}

Keywords: vancomycin, therapeutic drug monitoring, nephrotoxicity

\section{Introduction}

Vancomycin is a time-dependent antibiotic with bactericidal activity useful for treating patients with infections caused by Gram-positive microorganisms, including methicillin-resistant Staphylococcus aureus. It presents a 2 or 3 compartment pharmacokinetic profile and high interindividual variability, which result in the need for a routine therapeutic drug monitoring (TDM). Adverse effects associated with the use of this antibiotic include mainly those related to infusion and nephrotoxicity. Currently, these toxicities are related to long periods of treatment, concomitant nephrotoxic agents, high dosages, and high vancomycin plasma trough levels. ${ }^{1}$

Vancomycin has usually been associated with nephrotoxicity; nevertheless, the direct damage caused by this glycopeptide is still unknown. ${ }^{2}$ Vancomycin-induced nephrotoxicity is characterized by acute tubular necrosis (ATN) or interstitial damage, yet the majority of biopsy reports have described acute interstitial nephritis (ATIN) rather than ATN. This probably reflects publication bias; it indicates the existence of an allergic mechanism in some patients with vancomycin nephrotoxicity. ${ }^{3}$ In addition, to find both lesions on biopsy is uncommon. ${ }^{2}$ Also, poor definition of diagnosis may also limit early recognition and prompt intervention concerning vancomycin-induced nephrotoxicity. ${ }^{4}$ Since there are no clinical features or laboratory findings that can confirm these pathologies, a renal biopsy is mandatory to obtain an accurate diagnosis. ${ }^{5}$ 
We present a case of vancomycin nephrotoxicity with simultaneous histological lesions of ATIN and ATN confirmed by renal biopsy, originated by vancomycin intoxication related to the highest plasma trough levels described in literature.

\section{Case report}

Written informed consent was obtained from the patient described to have their case details published.

We report a case of vancomycin intoxication in a 46-yearold man with no known drug allergies, with a weight of $85 \mathrm{~kg}$ (body mass index: $25.66 \mathrm{~kg} / \mathrm{m}^{2}$ ) and normal renal function prior admission (glomerular filtration rate-modification of diet in renal disease [GFR-MDRD $4>60 \mathrm{~mL} / \mathrm{min}$ )

In July 2017, the patient was admitted to the emergency department due to headache, consciousness decrease, aphasia, and hypertensive crisis. He underwent a cranial computed tomography (CT) scanning, which diagnosed a massive cerebellar parenchymal hematoma and a vasogenic edema, with collapsing base cisterns and compressing the brainstem. Emergency neurosurgery was performed, setting up 2 external ventricular drains. Since the hypertensive crisis could not be controlled, the patient was admitted to the intensive care unit (ICU). The patient developed a multifactorial acute kidney injury (AKI) (serum creatinine [SCr]: $1.96 \mathrm{mg} / \mathrm{dL}$, AKI AKIN 2). Ten days after intervention, the patient developed a fever which was suspicious for a probable central nervous system infection, so a sample of cerebrospinal fluid (CSF) was cultured. Also, blood, bronchoalveolar secretion, and urine cultures were performed. Firstly, the patient was treated with amoxicillin/clavulanate, and after persistant fever for 2 days, the treatment was changed to piperacillin/tazobactam and new cultures were performed. On day 18, renal function returned to baseline values ( $\mathrm{SCr} 1.4 \mathrm{mg} / \mathrm{dL}$ ) but the patient's consciousness level was reduced, and fever was still present. CSF cultures were all negative, but compatible with bacterial ventriculitis; 4487 cells $/ \mathrm{mm}^{3}$ (normal range [NR]: $0-5$ cells $/ \mathrm{mm}^{3}$ ) with $90 \%$ polymorphonuclear disposition (NR: $1 \%-8 \%$ ), 2200 red blood cells/ $\mathrm{mm}^{3}$ (NR: $0-1$ cells/ $\mathrm{mm}^{3}$ ), $72 \mathrm{mg} / \mathrm{dL}$ glucose (NR: $50-80 \mathrm{mg} / \mathrm{dL}$ ), $7.3 \mathrm{mmol} / \mathrm{L}$ lactate (NR: $1-3 \mathrm{mmol} / \mathrm{L}$ ), and $930 \mathrm{mg} / \mathrm{dL}$ proteins (NR: $15-45 \mathrm{mg} / \mathrm{dL}$ ); then, antimicrobial treatment was changed to meropenem and linezolid. After 3-week treatment, showing no fever, all cultures showing negative results, and normalization of CSF biochemistry, the patient was discharged to a neurorehabilitation center.

Six days later, the patient was re-admitted to the emergency department due to fever, decreased consciousness, and bronchial secretions. At the emergency department, the patient presented secondary seizures and was admitted to ICU, where a subdural collection was observed. The patient underwent a surgical intervention by neurosurgeons to evacuate the subdural hematoma. After 7 days in the ICU, the patient was stable and admitted to the neurosurgery unit. The patient remained hemodynamically stable with normal kidney function ( $\mathrm{SCr} 1.2 \mathrm{mg} / \mathrm{dL}$ ) and urine volume, 1.3-2.1 L/day, until day 10 from re-admission, when he started presenting tremors and small seizures. Physicians suspected postsurgical meningitis; therefore, a new sample of CSF was studied and it presented pathological features: 118 cells $/ \mathrm{mm}^{3}$ (NR: $0-5$ cells $/ \mathrm{mm}^{3}$ ) with $35 \%$ polymorphonuclear disposition (NR: $1 \%-8 \%$ ), 700 red blood cells $/ \mathrm{mm}^{3}$ (NR: $0-1$ cells $/ \mathrm{mm}^{3}$ ), 23 $\mathrm{mg} / \mathrm{dL}$ glucose (NR: $50-80 \mathrm{mg} / \mathrm{dL}$ ), $8.1 \mathrm{mmol} / \mathrm{L}$ lactate (NR: $1-3 \mathrm{mmol} / \mathrm{L}$ ), and $106.9 \mathrm{mg} / \mathrm{dL}$ proteins (NR: $15-45 \mathrm{mg} /$ dL); CSF was also cultured. However, no microorganism was isolated. Following the latest recommendations of the Infectious Diseases Society of America guidelines to treat meningitis, the patient was treated with ceftazidime $2 \mathrm{~g} / 8$ hours and vancomycin $1 \mathrm{~g} / 8$ hours. ${ }^{6}$ After 5-day therapy, the patient presented an AKI AKIN 3 ( $\mathrm{SCr} 3.05 \mathrm{mg} / \mathrm{dL}$ ); so, vancomycin plasma levels (VPLs) were analyzed. Quantitative microsphere system immunoassay was used to determine VPL, of which the lowest detectable level is $3 \mu \mathrm{g} / \mathrm{mL}$ and the highest is $100 \mu \mathrm{g} / \mathrm{mL}$. Peak and trough levels of 77.11 and $63.60 \mu \mathrm{g} / \mathrm{mL}$, respectively, were obtained. After these results, vancomycin therapy was stopped and the patient was carried through a narrow TDM. Twenty-six hours after the last vancomycin dose, VPLs were still $61.53 \mu \mathrm{g} / \mathrm{mL}$. A total of 9 VPL determinations were performed until the patient presented undetectable values. In each determination, pharmacokinetic parameters were calculated, presenting a maximum value of half-life time of 94.7 hours and distribution volume of $121 \mathrm{~L}$. Also, area under the curve $(\mathrm{AUC})_{0-24 \mathrm{~h}}$ with the last vancomycin dose was calculated, presenting an exposition of $2,096 \mu \mathrm{g} / \mathrm{mL} * \mathrm{~h}$.

During the next few days, the patient developed severe renal impairment (SCr $10 \mathrm{mg} / \mathrm{dL}$ ) which initiated renal replacement therapy at day 12 due to fluid overload. The patient received intermittent hemodialysis with a high permeability membrane (FX CorDiax 60, Fresenius Medical Care, Hesse, Germany). This membrane removes up to $50 \%$ of the substances with a molecular weight $>550 \mathrm{Da}$ (Vancomycin is 1,500 Da). Because of progressive renal impairment, despite vancomycin withdrawal 12 days before, a renal biopsy was performed and an ATIN with severe tubular injury was observed; a diagnosis of vancomycin nephrotoxicity was made (SCr and VPL evolution shown at Figure 1). The patient did not receive steroid treatment because the delay of pathological diagnosis; clinical suspicion 


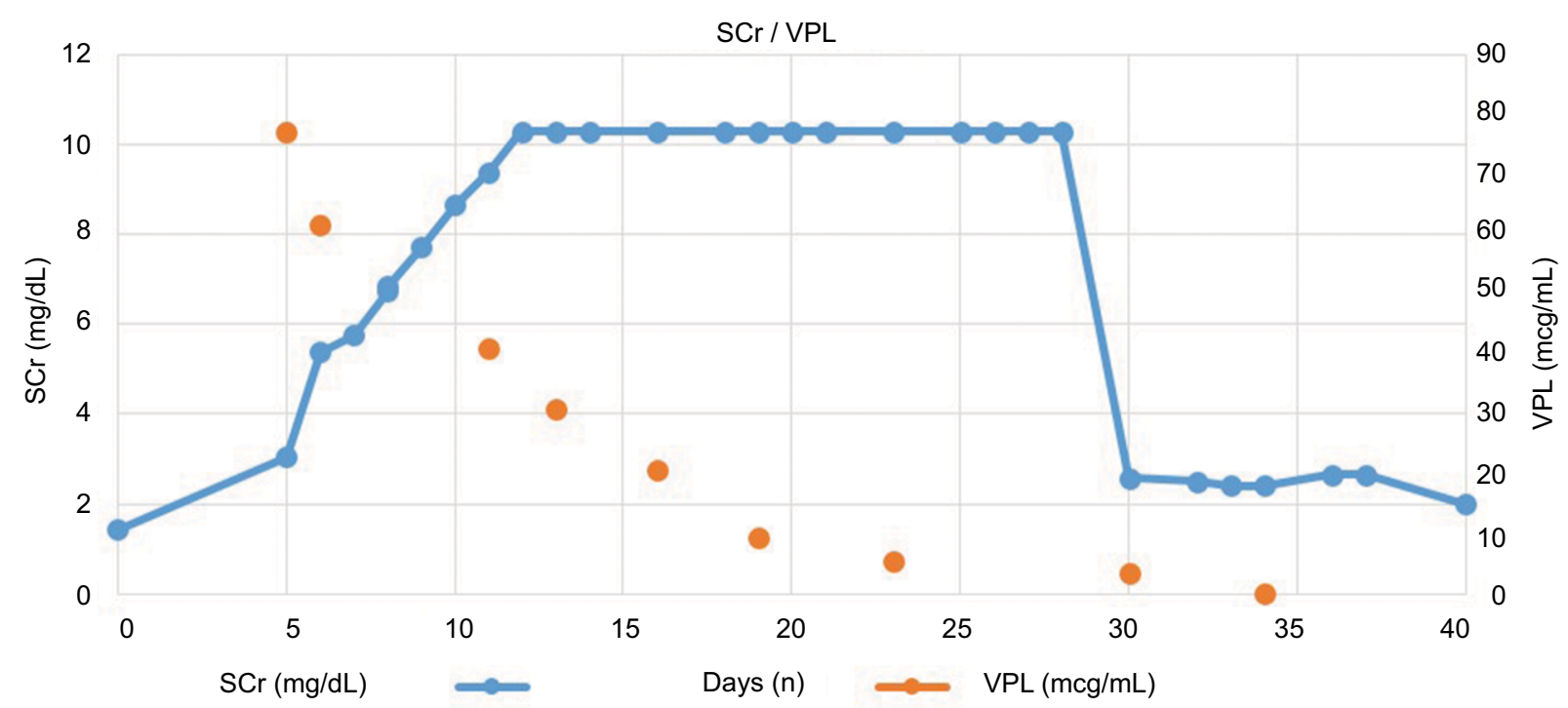

Figure I SCr and VPL evolution.

Notes: $\mathrm{SCr}$ values from day 12 to 28 represented as a plateau due to the patient undergoing hemodialysis sessions. These values could be underestimated. Abbreviations: $\mathrm{SCr}$, serum creatinine; VPL, vancomycin plasma level.

were ATN. After 1 month without vancomycin therapy, the patient presented undetectable VPL at day 34. The patient underwent intermittent hemodialysis over 17 days with complete recovery of renal function.

\section{Discussion}

It has been described that vancomycin trough plasma levels $>20 \mu \mathrm{g} / \mathrm{mL}$ or $\mathrm{AUC}_{0-24 \mathrm{~h}}>700 \mu \mathrm{g} / \mathrm{mL}^{*} \mathrm{~h}$ are related to nephrotoxicity. ${ }^{7}$ Nevertheless, few cases of ATIN and tubular injury related to vancomycin are described as a biopsy confirmation is needed.

To our knowledge, only 2 other cases of biopsy-proven nephrotoxicity with both ATIN and tubular injury with VPL determinations are described. One case described by Katikaneni et $\mathrm{al}^{8}$ presented a biopsy-proven ATIN and ATN after vancomycin treatment for a lung abscess, which after VPL determination showed a trough value of $49.4 \mu \mathrm{g} / \mathrm{mL}$, lower than in our case. In the case published by Htike et al, ${ }^{9}$ bacteremia caused by a coagulase-negative staphylococcus, also ATIN and ATN was confirmed after renal biopsy; VPLs were extracted and peaked at $141 \mu \mathrm{g} / \mathrm{mL}$. Even though this VPL is higher than in our case, there is no information about when this plasma level was extracted or if it was a peak or a trough level. Moreover, unlike our case, which had a total of 9 VPL determinations, the one they describe had just 1 VPL determination, and there is no information about total vancomycin washout and pharmacokinetic parameters in patients presenting an AKI by ATN and ATIN. We were able to describe a total vancomycin washout of a month thanks to the narrow TDM performed.
From all cases, and referring to trough levels, VPL in our patient was the highest one $(63.60 \mathrm{mcg} / \mathrm{mL})$, in spite of the case published by Htike et al, which presented a plasma level of $141 \mu \mathrm{g} / \mathrm{mL}$ without specifying whether it was Cmax, Cmin, or a sample extracted at another time.

Unlike our case, the other cases did not calculate additional pharmacokinetic parameters. The AUC observed in our patient was well above the value considered as a predictor of nephrotoxicity $\left(700 \mu \mathrm{g} / \mathrm{mL}^{*} \mathrm{~h}\right)$. Our plasma determinations show that after renal damage, vancomycin can persist at high levels for a long time in the patient, with the possibility that this long exposure can cause more renal damage.

In conclusion, early vancomycin TDM should be performed to avoid supratherapeutic plasma levels, which can lead to renal damage. As seen in our patient, antibiotic exposure could last around 1 month after last dose administration, worsening the patient's renal function several weeks after the end of therapy.

\section{Disclosure}

The authors report no conflicts of interest in this work.

\section{References}

1. Rybak M, Lomaestro B, Rotschafer JC, et al. Therapeutic Monitoring of Vancomycin in Adult Patients: A Consensus Review of the American Society of Health-System Pharmacists, the Infectious Diseases Society of America, and the Society of Infectious Diseases Pharmacists. Am J Heal Pharm. 2009;66:82-98.

2. Filippone EJ, Kraft WK, Farber JL. The Nephrotoxicity of Vancomycin. Clin Pharmacol Ther. 2017;102(3):459-469. 
3. Stokes MB. Vancomycin in the Kidney-A Novel Cast Nephropathy. $J A m$ Soc Nephrol. 2017;28(6):1669-1670.

4. Bamgbola O. Therapeutic Advances in Endocrinology and Metabolism. Review of vancomycin-induced renal toxicity: an update. Ther $A d v$ Endocrinol Metab. 2016;7(3):136-147.

5. Gelfand MS, Cleveland KO, Mazumder SA. Vancomycin-induced interstitial nephritis superimposed on coexisting renal disease: the importance of renal biopsy. Am J Med Sci. 2014;347(4):338-340.

6. Tunkel AR, Hasbun R, Bhimraj A. Clinical Infectious Diseases Executive Summary. Infectious Diseases Society of America's Clinical Practice Guidelines for Healthcare-Associated Ventriculits and Meningitis. 2017.
7. Zasowski EJ, Murray KP, Trinh TD, et al. Identification of Vancomycin Exposure-Toxicity Thresholds in Hospitalized Patients Receiving Intravenous Vancomycin. Antimicrob Agents Chemother. 2017;62(1).

8. Katikaneni M, Lwin L, Villanueva H, Yoo J. Acute Kidney Injury Associated With Vancomycin When Laxity Leads to Injury and Findings on Kidney Biopsy. Am J Ther. 2016;23(4):e1064-e1067.

9. Htike NL, Santoro J, Gilbert B, Elfenbein IB, Teehan G. Biopsy-proven vancomycin-associated interstitial nephritis and acute tubular necrosis. Clin Exp Nephrol. 2012;16(2):320-324.

\section{Publish your work in this journal}

Infection and Drug Resistance is an international, peer-reviewed openaccess journal that focuses on the optimal treatment of infection (bacterial, fungal and viral) and the development and institution of preventive strategies to minimize the development and spread of resistance. The journal is specifically concerned with the epidemiology of antibiotic resistance and the mechanisms of resistance development and diffusion in both hospitals and the community. The manuscript management system is completely online and includes a very quick and fair peerreview system, which is all easy to use. Visit http://www.dovepress.com/ testimonials.php to read real quotes from published authors. 